FRIDAY, 16 JUNE 2017

Biological agents in juvenile idiopathic arthritis: open issues

\section{OP0315 REASONS FOR DISCONTINUATION OF BIOLOGICAL AGENTS IN PATIENTS WITH JUVENILE IDIOPATHIC ARTHRITIS: DATA FROM THE PORTUGUESE REGISTER, REUMA.PT}

A.F. Mourão ${ }^{1}$, M. Eusébio ${ }^{2}$, J. Melo-Gomes ${ }^{3}$, F. Oliveira-Ramos ${ }^{4}$, F. Martins ${ }^{2}$, P. Estanqueiro ${ }^{5}$, M. Salgado ${ }^{5}$, M. Guedes ${ }^{6}$, M. Conde ${ }^{7}$, S. Carvalho ${ }^{8}$, J. Tavares-Costa ${ }^{9}$, C. Duarte ${ }^{10}$, I. Brito ${ }^{11}$, C. Furtado ${ }^{12}$, A. Rodrigues ${ }^{13}$, G. Sequeira ${ }^{14}$, R. Campanilho-Marques ${ }^{4}$, J. Branco ${ }^{15}$, M.J. Santos ${ }^{16}$, J. Eurico-Fonseca ${ }^{17}, \mathrm{H}$. Canhão ${ }^{18} \cdot{ }^{1}$ Rheumatology, CHLO, EPE; ${ }^{2} S P R$; ${ }^{3}$ Rheumatology, Portuguese Institute of Rheumatology; ${ }^{4}$ Rheumatology, Pediatric Reumatology Unit, CHLN, EPE, Lisbon; ${ }^{5}$ Pediatrics, CHUC, Coimbra; ${ }^{6}$ Pediatrics, Centro Hospitalar do Porto - Hospital de Santo Antonio, Porto; ${ }^{7}$ Pediatrics, Hospital Dona Estefânia, Lisbon; ${ }^{8}$ Pediatrics, Centro Hospitalar do Médio-Ave, Famalicão; ${ }^{9}$ Rheumatology, ULSAM - Hospital Conde de Bertiandos, Ponte de Lima, Viana do Castelo; ${ }^{10}$ Rheumatology, Centro Hospitalar Universitário de Coimbra, Coimbra; ${ }^{11}$ Rheumatology, Centro Hospitalar São João, Porto; ${ }^{12}$ Rheumatology, Hospital do Divino Espírito Santo, São Miguel, Ponta Delgada; ${ }^{13}$ Rheumatology, Hospital de Santo Espírito, Angra do Heroísmo, Angra do Heroísmo; ${ }^{14}$ Rheumatology, Centro Hospitalar de Faro, Faro; ${ }^{15}$ CEDOC, Nova Medical School, Lisbon; ${ }^{16}$ Rheumatology, Hospital Garcia de Orta, Almada, Almada; ${ }^{17}$ Rheumatology research Unit, Faculdade de Medicina de Lisboa; ${ }^{18}$ CEDOC, EpiDoC Unit, Nova Medical School, Lisbon, Portugal

Background: Persistence on medication mainly reflects both effectiveness and safety of a drug. Understanding the reasons to stop bDMARD in routine clinical practice can help to better define the efficacy and safety of biologic medications in children with juvenile idiopathic arthritis (JIA).

Objectives: To investigate persistence on treatment and the reasons for discontinuation of the first biological in patients with JIA.

Methods: Portuguese patients with JIA registered in Reuma.pt who started a bDMARD were analyzed. Persistence was defined as the time between treatment initiation and discontinuation of the first bDMARD. The mean time until discontinuation was calculated using Cox regression survival estimates and the reasons for discontinuation of the first bDMARD were registered.

Results: Of the 1724 JIA patients registered in Reuma.pt, 319 received biological therapy, $62 \%$ (198) female. The mean age at disease onset was $7.7 \pm 4.8$ years and the mean time between the beginning of JIA and the first bDMARD was $8.2 \pm 9.4$ years. The mean disease duration was $13.7 \pm 10.7$ years and the mean age at the beginning of biological therapy was $15.8 \pm 9.4$ years. The distribution of JIA subtypes was: $19.1 \%$ polyarticular RF-negative, $17.2 \%$ enthesitis-related arthritis, $16.6 \%$ polyarticular RF-positive, $16 \%$ extended oligoarticular, $13.5 \%$ persistent oligoarticular, $12 \%$ systemic JIA and $0.9 \%$ had undifferentiated arthritis. Considering the whole group, 53.2\% have had extra-articular manifestations and $18.4 \%$ have or had had uveitis since the beginning of the disease. Persistence on treatment, before discontinuation (due to any cause) was 34.7 months (range: 0.03-182 months) adjusted for gender, biological therapy, JIA subtype, age at the beginning of biological therapy, and disease duration until initiating first bDMARD. The major reasons for drug discontinuation was inefficacy $(49.6 \%)$, remission $(14.2 \%)$, adverse events (10.6\%), patient decision (1.6\%) and pregnancy planning (1.4\%). In $22.7 \%$ the reason was not specified.

Conclusions: Almost half of the JIA patients stop the first biological agent, due to lack of response, reinforcing the need for the existence of several treatment options fully studied in JIA.

Disclosure of Interest: None declared

DOI: 10.1136/annrheumdis-2017-eular.2959

\section{OP0316 DURATION OF CLINICAL REMISSION AND FLARE RATES IN PATIENTS WITH JUVENILE IDIOPATHIC ARTHRITIS AFTER WITHDRAWAL OF BIOLOGICAL TREATMENT (PRELIMINARY DATA)}

E. Kashchenko ${ }^{1}$, E. Alexeeva ${ }^{1,2}$, T. Bzarova ${ }^{1,2}$, S. Valieva ${ }^{1}$, K. Isaeva $^{1}$, R. Denisova ${ }^{1}$, O. Lomakina $^{1}$, T. Sleptsova ${ }^{1}$, M. Soloshenko $^{1}$, A. Karaseva ${ }^{1}$ ${ }^{1}$ Federal State Autonomous Institution "National Scientific and Practical Center of Children's Health" of the Ministry of Healthcare of the Russian Federation; ${ }^{2}$ I.M. Sechenov First Moscow State Medical University, Moscow, Russian Federation

Background: Prolonged therapy with biological agents (BAs) may cause adverse events, which leads to the necessity of discontinuation of BAs in patients with juvenile idiopathic arthritis (JIA), once complete disease quiescence has been achieved.

Objectives: To estimate the length of time in clinical remission and time to disease flare after discontinuation of treatment with BAs.

Methods: 83 patients with JIA (33 - with systemic onset, 50 - with oligo- or polyarticular arthritis) were included in the survey. The cohort was 34,9\% (29 patients) male and $65,1 \%$ (54 patients) female with a mean age of $11 \pm 3,69$ years (range 5-17 years). All patients with systemic JIA (sJIA) were treated with tocilizumab, $35(70 \%)$ patients with other types of JIA received etanercept, 15
(30\%) - adalimumab. $14(42,4 \%)$ patients with SJIA additionally got methotrexate, $5(15,1 \%)$ - cyclosporine, $5(15,1 \%)$ - glucocorticoids, 1 (3,0\%) - leflunomide; $9(25,7 \%)$ and $7(46,6 \%)$ patients took combination therapy of etanercept or adalimumab and methotrexate. Patients were randomized into 2 main groups using envelope method: in a first group a BA was discontinued abruptly, while in the second it was tapered gradually by increasing injection/infusion interval.

Results: Duration of inactive disease/clinical remission during tocilizumab treatment was $43 \pm 12,16 / 37 \pm 12,16$ months, etanercept $-40 \pm 13,13 / 34 \pm 13,17$ months, adalimumab - 48 $\pm 11,9 / 40 \pm 12,06$ months. Tocilizumab, etanercept, adalimumab were discontinued in $22(66,6 \%), 28(80,0 \%), 11(73,3 \%)$ patients and were tapered by increasing injection/infusion interval in $11(33,4 \%), 7(20,0 \%), 4$ $(26,7 \%)$ cases, respectively. After withdrawal of tocilizumab, etanercept and adalimumab $29(87,9 \%), 24(68,6 \%), 6(40,0 \%)$ patients remained in remission of JIA for $6 \pm 10,23(1-48)$ months, $6 \pm 5,07$ (1-20) months and $6 \pm 13,33$ (4-38) months, respectively. $4(12,1 \%), 11(31,4 \%), 9(60,0 \%)$ patients flared within $8 \pm 5,65(6-18)$ months, $5,5 \pm 3,49(1,5-12)$ months and $4 \pm 4,64(1-13)$ months after discontinuation of tocilizumab, etanercept and adalimumab, respectively.

Conclusions: Withdrawal of BAs after clinical remission for more than 1,5 years was not associated with a disease exacerbation in more than $70 \%$ of patients with JIA. A mean duration of clinical remission after withdrawal of BAs was 6 months. Disclosure of Interest: E. Kashchenko Grant/research support from: Novartis, E. Alexeeva Grant/research support from: Roche, Abbott, Pfizer, Bristol-Myers Squibb, Centocor, Novartis, Speakers bureau: Roche, Merck Sharp \& Dohme, Abbott, Bristol-Myers Squibb, Medac, Novartis, Pfizer, T. Bzarova Grant/research support from: Roche, Pfizer, Novartis, Speakers bureau: Roche, Merck Sharp \& Dohme, Abbott, Pfizer, S. Valieva Grant/research support from: Roche, BristolMyers Squibb, Speakers bureau: Roche, Merck Sharp \& Dohme, Bristol-Myers Squibb, Medac, Novartis, K. Isaeva Grant/research support from: Roche, Novartis, R. Denisova Grant/research support from: Roche, Centocor, Novartis, Speakers bureau: Roche, Merck Sharp \& Dohme, Abbott, Medac, O. Lomakina: None declared, T. Sleptsova Grant/research support from: Centocor, Speakers bureau: Merck Sharp \& Dohme, Bristol-Myers Squibb, M. Soloshenko: None declared, A. Karaseva: None declared DOI: 10.1136/annrheumdis-2017-eular.5756

\section{FRIDAY, 16 JUNE 2017 Health equity and economy - a vital relationship \\ OP0317-PARE AN INDEPENDENT REVIEW OF PEOPLE WITH RHEUMATOID ARTHRITIS (RA) AND THEIR CAREGIVER'S LOST WORK TIME}

A. Bosworth ${ }^{1}$, C. Jacklin ${ }^{1}$, T. Burke ${ }^{2}$, A. Rose ${ }^{2}$, I. Jacob ${ }^{2}$, S. Verstappen ${ }^{3}$. ${ }^{1}$ National Rheumatoid Arthritis Society (NRAS), Maidenhead; ${ }^{2} \mathrm{HCD}$ Economics, Warrington; ${ }^{3}$ Arthritis Research UK Centre for Epidemiology Division of Musculoskeletal and Dermatological Sciences, University of Manchester, Manchester, United Kingdom

Background: The National Rheumatoid Arthritis Society (NRAS) is the only patient-led charity in the UK focussing specifically on rheumatoid arthritis (RA) with the key responsibility of raising awareness of the impact and burden of RA. There is a lack of information about the costs and impact of RA on work in the European community; in particular the wider societal costs such as people with RA not being able to perform their job to their best ability, losing days of work due to their RA condition, and the domino effect on caregiver employment.

Objectives: To quantify the burden of RA not only on the healthcare system, but also the wider societal costs associated with RA.

Methods: In 2016 NRAS undertook a partnership with the University of Chester's commercial economics partner HCD Economics who conducted the multinational Burden of Rheumatoid Arthritis: Socioeconomic Survey (BRASS). The study used a bottom-up approach to quantify the burden of disease for people living with RA across 10 European countries including France, Germany, Italy, Spain, Denmark, Sweden, Hungary, Poland, Romania and the UK. The study collected information from patients and physicians on factors associated with managing RA, plus RA sufferers' views on life and workplace impact. It collected information on the resource use and cost of patient care including treatment costs, hospitalisation, tests, and examinations. The wider societal costs included; cost of travel to appointments, requirements for aids/equipment, informal care (non-professional), ability in employment, early retirement due to RA. Work time missed, work and activity impairment were measured using the Work Productivity and Activity Impairment (WPAI) questionnaire.

Results: Voluntary data were collected from 1782 patient forms, of which the average age was 55 years, $1274(71 \%)$ were female and $833(48 \%)$ were currently in work. This study found, on average, persons with RA lose one day of every 4 working days due to not being able to perform their job to their best ability, and completely miss $7 \%$ of work time over a 7 day period due to their RA (sample $n$ of 646). In addition to not being able to perform their job to their best ability, almost a third of working persons with RA also had impairment in daily living activities such as shopping and work around the house (sample $n$ of 735). This study also found family/friends have to care for $16 \%$ of RA sufferers. This care resulted in reduced employment or inability to work for $25 \%$ of family/friend caregivers (sample $n$ of 121) 